\title{
Research on the Paths of Chengdu-Chongqing Cultural Cooperation from the Perspective of Cultural Community
}

\author{
Shihong Wang ${ }^{1, *} \mathrm{Yu} \mathrm{Liu}{ }^{1}$ \\ ${ }^{1}$ School of Public Affairs and Administration, University of Electronic Science and Technology of China, \\ Chengdu, China \\ ${ }^{*}$ Corresponding author. Email: $739275817 @ q q . c o m$
}

\begin{abstract}
Cultural exchange plays an important role in establishing Chengdu-Chongqing economic circle and strengthening the new vitality of Chengdu-Chongqing development, and it is of great significance to explore how to promote Chengdu-Chongqing cultural exchange and cooperation from the perspective of cultural community. At present, the cultural exchanges between Chengdu and Chongqing enjoy favorable foundations. However, there is still room for improvement in the protection of historical and cultural resources, the positioning of urban culture, and the agglomeration and development of cultural industries. Based on the situation of Chengdu-Chongqing cultural cooperation in recent years, this paper makes research from the aspects of the coordination mechanism, cultural resources, cultural brands and cultural industries, etc., trying to explore effective paths for the cultural cooperation and exchange between Chengdu and Chongqing. The Chengdu-Chongqing cultural cooperation and exchange will lead the regional cultural exchange and innovation, and also promote the high-quality construction of Chengdu-Chongqing economic circle.
\end{abstract}

Keywords: Chengdu-Chongqing economic circle, cultural exchange, cultural community, paths of cultural cooperation

\section{INTRODUCTION}

On January 3, 2020, the sixth meeting of Financial and Economic Commission of the CPC Central Committee discussed the issue of promoting the construction of Twin-city Economic Circle in Chengdu-Chongqing Region. Chengdu and Chongqing are the economic and cultural development centers in the twin-city economic circle. Economic growth lays the foundation for culture and cultural development enables economy. The cultural exchanges and cooperation between the two places not only meet the demands of economic integration, but also promote the construction of regional cultural community. The formation of Chengdu-Chongqing regional cultural community is an important link in the successful establishment of the Chengdu-Chongqing Twincity Economic Circle, which can enhance urban cohesion and social identity [1]. Chengdu and

*Project: This article is a phased research result of the Tianfu cultural research project "Chengdu and Chongqing Cultural City Exchange and Cooperation Against the Background of the Two-City Economic Circle"
Chongqing have close cultural ties and share profound origins, with distinct personalities and obvious differences of their own at the same time. Therefore, the study of cultural exchanges and cooperation between the two cities is the only way to promote the sustainable development of twincity economic circle. By sorting out the current situation of Chengdu-Chongqing cultural cooperation, this paper attempts to analyze the deficiencies in the aspects of exchanges on the protection of history and culture, common cultural characteristics of cities, and cultural industry development in the current situation of cooperation from the perspective of cultural community, and make corresponding path research in the hope of promoting the cultural exchange between ChengduChongqing cities. 


\section{ANALYSIS ON THE CURRENT SITUATION AND PROBLEMS OF CHENGDU- CHONGQING CULTURAL COOPERATION}

Chengdu and Chongqing have profound cultural history, abundant cultural resources and are highly inclusive. For a long time, the two cities have been learning from each other and working together to bring forth new ideas, and thus telling a wonderful "tale of two cities". Nowadays, the ChengduChongqing Twin-city Economic Circle has become a national strategy. In order to realize the construction of regional cultural community in the two cities [2] and further release the new vitality of cultural development, it is necessary to sort out the current situation of Chengdu-Chongqing cultural cooperation and solve the crux of cooperation, so as to make practical reference to the path exploration.

\section{A. The current situation of Chengdu-Chongqing cultural cooperation}

1) Long term and profound foundation: As early as more than 10 years ago, Chengdu and Chongqing began to actively promote cultural exchanges between the two places: since 2004, Sichuan and Chongqing have signed a number of agreements, including the "Agreement on Strengthening Cultural Cooperation and Seeking Cultural Development Between Sichuan and Chongqing", which has promoted the top-level design improvement of cultural exchanges between the two provinces and cities, as well as cooperation in specific fields like tourism, culture and sports and broadcasting, etc. The first Sichuan-Chongqing Cultural Cooperation Forum hosted by Chongqing Federation of Literary and Art Circles and Sichuan Provincial Federation of Literary and Art Circles was officially held in 2007, which promoted the deeper discussion of Sichuan-Chongqing culture and formed the annual Sichuan-Chongqing cultural exchange and cooperation platform. Since then, the forum has maintained extensive regional cultural influence. In 2011, the "Framework Agreement on Regional Cooperation for Urban and Rural Cultural Development of Chengdu and Chongqing", which marked a new dimension of cultural exchanges and cooperation between Chengdu and Chongqing, was officially finalized.

2) Rich content including drama, music, calligraphy and painting: Cultural exchanges between the two places continue. Chengdu and Chongqing jointly build three quality tourism performances around Sichuan opera and the Three Kingdoms, and support the creation of Sichuan opera "Good Woman and Bad Woman", acrobatics drama "Hua Mulan", and children's drama "Proud
Big Cock". According to the "Twenty Four Gigaku", they also held a special performance of folk music "Lotus in Western Rhythm" and music drama "Romance on the Silk Road". Chengdu has also actively integrated its art resources and held exhibitions such as "Paintings and Calligraphy Art Exhibition of the Eight Eccentric Artists in Yangzhou" and "Witness the Great Southwest in 'the Historical Records'" in cooperation with several museums in accordance with the characteristics of the province, which triggered the upsurge of Chengdu-Chongqing people's activity of seeing exhibition and also made the culture burst into new vitality in the exchange. On the other hand, Chongqing has also organized exhibitions by linking the efforts of art academies in the two places together, such as "The Spirit of Chinese Contemporary Print" and "Watercolor Scene - the first Chongqing and Sichuan Watercolor Art Joint Exhibition", etc.

3) Interconnection between the governments in various forms: In recent years, Chengdu and Chongqing have also conducted deeper cooperation and exchanges in cultural system, cultural resources, cultural brands and cultural industries. The Chengdu-Chongqing Cultural Exchange Coordination Group has been set up in the two places, and annual work exchange meetings have been held to share experience in the cultural field, which has promoted the improvement of cultural industry development, cultural system reform, artistic creation and production, public cultural service system construction and other aspects in the two places. In the tourism industry, the two cities will gradually integrate their own distinctive cultural resources and promote the construction of demonstration cities of cultural tourism cooperation, so as to excavate the common cultural connotation and build Chengdu-Chongqing highquality tourism platform, which will increase the endogenous power for the overall development of tourism in the two places. They also actively promote the establishment of the university union of twin-city economic circle, strengthen the exchange and communication of ChengduChongqing higher education, and jointly promote the high-quality development of education in both places.

\section{B. Problems of Chengdu-Chongqing Cultural Cooperation and the causes}

1) Poor protection of historical and cultural resources: Although there are a considerable amount of high-quality cultural resources in Chengdu and Chongqing, the protection work is 
generally confined to the traditional mode, and the promotion effect of cultural exchange is not perfect, and the protection and utilization of cultural relics in Chengdu and Chongqing also lack linkage and high efficiency. First of all, there is insufficient awareness of the protection of historical and cultural resources. The public's understanding of the importance of historical and cultural resources needs to be improved, and the research on ancient cultural relics and ancient cultures with great historical significance needs to be further intensified. At the same time, the classification work of the cultural heritages in ChengduChongqing is lagging behind, and the information exchange on the cultural phenomena such as the Anti-Japanese War culture produced under the same background is less. The comprehensive investigation and information exchange of the common cultural resources of the two famous historical and cultural cities, Chengdu and Chongqing need to be strengthened.

2) The urban culture positioning of Chengdu and Chongqing needs to be more accurate: Chongqing and Chengdu are respectively among the first and second batch of cultural reform pilot cities in China, and they are both pioneers of cultural reform in their respective regions. However, in recent years, there are still some deficiencies in the building of cultural brands in the two places. The regional cultural theme is not prominent enough and the image is relatively indistinct [3]. The positioning of the two cities is still unclear. Chengdu has put forward more than ten cultural orientations of the city, such as Tianfu (land of abundance) and the Capital of Delicacies, etc.; and Chongqing also has such urban cultural orientations as "Mountain City" and "Ren Ren Chongqing (the image symbol of Chongqing, with 'double jubilation', which means 重庆 literally, as the creative theme and two happy people forming a 'qing, 庆', which reveals the historical origin of the name of Chongqing)", etc. After many cultural symbols are widely publicized, the image of the city becomes blurred in the eyes of the public, so that the two places have failed to establish a recognized and distinctive cultural image. The image publicity of the two cities' culture has not reached a perfect harmony. The two cities promoted many well-made promotional videos like "Chengdu, a City Pulling You In" and "Beautiful Chongqing" which show many cultural elements, yet fail to shape a distinct theme of ChengduChongqing culture. In addition, although $\mathrm{Ba}-\mathrm{Shu}$ culture is mainly promoted in the two places, Chengyu and Chongqing have little cooperation in image building and publicity, and the role of cultural image positioning in promoting the cooperation and exchange of Chengdu-Chongqing culture in the two places still needs to be improved.

3) The cultural industry agglomeration is not enough: The cultural industry is a major growth pole for cultural exchanges and cooperation. The cooperation of cultural industry can bring about not only the flow of production factors, the rational allocation of resources and the economic growth driven by the twin-city economic circle, but also the flow of cultural factors, the construction of regional cultural community and the deepening of cultural exchanges [4]. But at present, the driving force of the cultural industry is not enough, and the construction of Chengdu-Chongqing cultural market needs to be strengthened. The cultural trade between the two places lacks the support of an orderly cultural market, the mechanism of cultural coordinated development is not perfect, the integration and openness of the cultural market is not enough, and the overall competitiveness of the cultural industry is still insufficient. At the same time, the integration degree of cultural industries in the two places is not sufficient, and the cultural integration of Chengdu-Chongqing has not fully developed. The common innovation platform of Chengdu and Chongqing has not achieved unified planning, and the cultural and creative products are thus seriously homogenized. The agglomeration scale of cultural tourism industry is small, the allocation of cultural resources is poor, and there is a lack of quality routes, cultural tourism festivals and literary brands. The two cultural industries still need to be improved to promote the sustainable development of Chengdu-Chongqing cultural exchange.

\section{THE PATH CONSTRUCTION OF CHENGDU-CHONGQING CULTURAL COOPERATION}

\section{A. Joint cooperation and coordination mechanism}

In order to successfully construct the ChengduChongqing cultural cooperation path, it is necessary to start from the perspective of cultural community and establish institutionalized and normalized cultural consultation and dialogue mechanism.

Compared with the Beijing-Tianjin-Hebei region and the Yangtze River Delta Region, the twin city of Chengdu and Chongqing have fewer administrative divisions and less difficulty in communication and consultation and coordination. Therefore, the establishment of institutionalized and normalized consultation and dialogue 
mechanism has more advantages. The governments of Chengdu and Chongqing can establish a closer high-level coordination and interaction system, such as meeting mode institutionalization and major project supervision and coordination on a regular basis. This will strengthen the normalized consultation and communication in cultural aspect, promote the exchange of needed goods between the two cities, and improve the cultural policy coordination ability between the two cities. In addition, Chengdu and Chongqing can establish a trans-administrative cultural coordination management organization, define its functional scope, improve its evaluation and supervision system, and constantly improve its functions and responsibilities. In this way, a linkage state of superior guidance, local coordination and department cooperation can be formed, so that the organization can timely coordinate the problems in regional cultural cooperation and exchange, and provide institutional guarantee for ChengduChongqing to build cultural exchange and cooperation.

\section{B. Jointly protecting historical and cultural resources}

After the smooth cooperation mechanism is established, the protection of cultural resources should also be strengthened to consolidate the material basis of cultural cooperation between the two places.

First of all, it is necessary to conduct in-depth research on the material and cultural heritage, intangible cultural heritage, various folk activities, ethnic festivals and other gathering activities in the two places to deeply develop their cultural connotation, maintain the traditional core of ancient culture, and expand the cooperation and exchange of cultural resources [5]. Chengdu and Chongqing should also establish a shared data platform, actively share the collection of ancient books and cultural relics, and improve the dynamic review mechanism. On this basis, it can continue to explore the unique connotation of traditional culture through the academic research work conducted by universities and research institutes, etc. It is necessary to integrate the fragmented contents restore the original appearance of traditional culture, and scientifically identify the excellent genes of traditional culture in ChengduChongqing region through the study of historical culture and ancient cultural relics. In addition, there are some important heritage sites under state protection in Chengdu and Chongqing. Not outstanding as they are compared with sites across the country, they can significantly enhance the cultural competitiveness of the region if they are managed in a refined way. For example, the advantages of Chongqing with red relics in the modern times and Chengdu with ancient cultural relics can be given into full play, and they can compensate for each other through cross-border travel routes.

\section{Creating a distinct cultural brand}

Based on the cooperation mechanism and material basis, it is necessary to create a distinct regional cultural brand and expand the prospect of Chengdu-Chongqing cultural exchange.

The both sides of Chengdu and Chongqing should make overall scientific planning, and produce customized cultural and creative products based on Chengdu-Chongqing characteristic culture such as panda and hotpot, etc., and improve domestic and foreign popularity through online and offline sales. In addition, they should strengthen brand design and marketing publicity, build a famous brand featured in Chengdu-Chongqing economic circle, carry out multi-dimensional marketing relying on the industrial foundation, and make full use of various publicity platforms. Besides, favorable policies should be strengthened to make full use of the traffic advantages of large airports of the two places, and certain visa preferential policies should be given to attract international tourists, so as to smooth the cultural communication channels between ChengduChongqing and the world. Moreover, a healthy cultural exchange ecology featuring commodity exchange, unimpeded personnel flow, artistic communication and data connectivity can be built in Chengdu-Chongqing by means of basic transportation facilities, holding joint exhibitions and performances, carrying out cultural product associations and building cultural digital platforms. At the same time, it is necessary to strengthen the publicity, the use of public accounts, weibo and other forms, to carry out integrated publicity to Chengdu and Chongqing and thus enhance the impression of Chengdu-Chongqing community among the masses and strengthen brand cognition.

\section{Jointly promoting the development of cultural industries}

It is an important measure of promoting the sustainable cultural exchange between Chengdu and Chongqing to promote the cluster development of cultural industry and seek the mutual integration and intercommunication between the two places

As innovative cities in China, Chongqing and Chengdu should promote cultural innovation by means of technological innovation and theoretical innovation. Relying on the existing mature industrial chain, they should integrate into the cultural inheritance and the Internet technology flexibly, so as to create the new format of "culture $+"$ industry development, realize the cultural 
transformation and upgrading of ChengduChongqing cities, and add vitality to the cultural development of the two places. It is necessary to intensify the development of cultural creativity, cultivate innovative enterprises with original brands, build leading cultural and creative enterprises in China, and form a favorable environment for the development of cultural creativity [6]. More importantly, the export of cultural products, such as Sichuan opera and Shu embroidery should be strengthened. It is necessary not only to make use of official channels for exchanges between art troupes and museums, but also make activities popular among the masses. The governments can subsidize local cultural and creative products with local characteristics, encourage them to go out, expand the audience group by the power of the market, and improve the popularity of characteristic culture. And the branding of Chongqing's local hotpot and beer, etc. can be strengthened and extended its influence to the economic circle and ever beyond it, so as to expand product audience to improve the degree of integration of Chengdu-Chongqing culture

\section{CONCLUSION}

Regional culture can promote the overall order of the city and the establishment of common ideals. From the perspective of cultural community, promoting Chengdu-Chongqing cultural cooperation has a great impact on enhancing the interest correlation and direction consistency of the two places, and also has a boost effect on Chengdu and Chongqing to build a twin-city economic circle and maintain the development vitality. At present, there are still some problems, such as poor cultural resources, accurate cultural positioning, and insufficient cultural industry agglomeration in Chengdu-Chongqing cultural cooperation. This paper provides research paths from mechanism building, resource protection, brand publicity and industry integration, and provides reference from system to specific countermeasures for promoting Chengdu-Chongqing cultural cooperation. However, this paper does not show a more detailed data analysis of the current situation of ChengduChongqing cooperation, and lacks sufficient quantitative standards generally. In the future research, quantitative analysis can be introduced to provide more detailed theoretical analysis and more accurate research paths for Chengdu-Chongqing cultural cooperation.

\section{References}

[1] Huang Yulong, Zeng Chao. Research on Cultural Cooperation in the Guangdong-Hong Kong-Macao Greater Bay Area: A Perspective of Cultural Community $[\mathrm{J}]$.
Journal of Guangzhou University (Social Science Edition), 2008,17(10): 59-65. (in Chinese)

[2] Fu Caiwu, Yan Xingrou. On the Construction of Chinese National Cultural Community in the 21st Century [J]. Journal of Central China Normal University Humanities and Social Sciences, 2016, 55 (05): 63-74. (in Chinese)

[3] Wang Ping. Research Report on Integrated Development of Cultural and Tourism in Chengdu Plain Economic Zone [N]. China Social Science, 2020-01-08 (008). (in Chinese)

[4] Meng Dongfang. Policy Effects, Problems and Development Countermeasures of Modern Cultural Industry System [J]. Chinese Public Administration, 2018(12): 151-153. (in Chinese)

[5] Zhang Chenjie. Research on the Conservation of Historiccultural Heritage of Geographical Names: Take Streets' Historical Names of Shanghai Old Town as an Example [J]. Urban Studies, 2017, 24(11): 20-24. (in Chinese)

[6] Zhang Youlin. Research on Cultural Resource Development and Development Model of Chengdu's Cultural Leisure Industry [J]. Social Scientist, 2020(01): 90-98. (in Chinese) 